\title{
Evaluación objetiva: el punto de vista de los estudiantes
}

Ínigo Noriega Echevarría

\section{Introducción}

Para cualquier estudiante, la evaluación es un punto de radical importancia en su proceso formativo no sólo como mecanismo de garantía de adquisición de competencias y conocimientos, sino también, en un importante grado, como mecanismo 'llave' para avanzar en dicho proceso.

En el caso de los estudiantes de medicina estamos sometidos a un largo proceso de evaluación, que se desarrolla desde nuestra entrada en las facultades de medicina con la prueba de selectividad, hasta la realización del examen MIR para acceder a la formación especializada.

Un cambio en el modelo de docencia debe conllevar así mismo un cambio en el modelo de evaluación, dado que ésta debe formar parte integral del desarrollo docente de una asignatura en un proceso continuo de aprendizaje. Por lo tanto, en los próximos años, no podremos decir que hemos conseguido alcanzar un auténtico cambio metodológico con la implantación de los nuevos planes de estudio si no se acompaña de un cambio igual de importante en los métodos de evaluación.

El Consejo Estatal de Estudiantes de Medicina (CEEM), como órgano que de manera legítima ostenta la representación de los estudiantes de nuestro país, a través de las delegaciones y consejos hemos tratado en varias ocasiones distintos temas y debates concernientes a nuestra evaluación. En el momento presente, la evaluación de los estudiantes de medicina se enfrenta a dos retos: la actualización de las metodologías docentes con la adaptación al Espacio Europeo de Educación Superior (EEES) en los nuevos planes y la adaptación del examen MIR a lo establecido por la Ley de Ordenación de las Profesiones Sanitarias (LOPS) [1]. Desde el CEEM queremos garantizar que ambos procesos se realicen atendiendo a criterios de objetividad y equidad.

\section{Evaluación objetiva}

Si hablamos de evaluación objetiva debemos tener claro cuál es el auténtico significado de ambos términos. De acuerdo con el diccionario de la Real Academia Española, algo es objetivo cuando es desinteresado y desapasionado y perteneciente o relativo al objeto en sí mismo, con independencia de la propia manera de pensar o de sentir. Si nos fijamos, por otro lado, en la palabra 'evaluación', tenemos que se trata de la acción de estimar los conocimientos, aptitudes y rendimiento de los alumnos. Para los estudiantes también posee un componente importante de elemento acreditativo de la adquisición de esos conocimientos y competencias que les permite avanzar en su formación.

Por lo tanto, cuando perseguimos una evaluación objetiva debemos buscar elementos que permitan valorar la totalidad de los conocimientos, las aptitudes y el rendimiento del estudiante, independientemente de la manera de pensar o sentir del evaluador. En una carrera como la nuestra, de alto componente humano en la práctica diaria, encontrar un balance adecuado entre un método que nos permite valorar de manera minuciosa el mayor número de elementos posible, sin entrar en el campo de la subjetividad del evaluador, será especialmente complejo.
Representante de alumnos, 4. ${ }^{\circ}$ curso. Facultad de Medicina. UAM.

Presidente del Consejo Estatal de Estudiantes de Medicina (CEEM).

E-mail secretaria@ceem.org.es 


\section{Estado actual de la evaluación del alumno de medicina en España}

La evaluación del estudiante de medicina a lo largo de su carrera es uno de los puntos más conflictivos de su paso por la universidad. De hecho, la evaluación puede llegar a ser uno de los puntos que centre el proceso de aprendizaje para el alumno, sobre todo en determinados planes de estudio, en los que la existencia de determinadas asignaturas denominadas 'llave' pueden cerrar el paso a una determinada asignatura o, incluso, a un curso entero [2]. Por ello, muchas veces los alumnos centran su aprendizaje en el esfuerzo por aprobar, dejando de lado en numerosas ocasiones la motivación como motor del proceso.

A lo largo de la carrera, los estudiantes nos enfrentamos a la evaluación de materias muy distintas entre sí. Empezamos con las materias básicas de contenidos predominantemente teóricos para ir avanzando poco a poco hacía las materias clínicas, en las cuales las evaluación de las competencias prácticas van (o más bien deberían ir) en aumento. Incluso dentro de los conocimientos teóricos, las diferencias entre las distintas asignaturas parecerían aconsejar la adaptación de los métodos de evaluación. Sin embargo, a día de hoy, la evaluación de los alumnos en nuestro país se basa fundamentalmente en dos modalidades:

- Examen multirrespuesta o tipo test. En este tipo de exámenes, el alumno debe elegir una o más respuestas a una determinada pregunta de entre las propuestas. Método de fácil corrección en el que el corrector difícilmente puede entrar en valoraciones subjetivas, pero que sin embargo deja de lado el trabajo de desarrollo por parte del alumno. Podríamos incluir aquí, por su similitud, las preguntas de tipo 'verdadero o falso.

- Preguntas de desarrollo. Ante un tema o una cuestión propuestos, el alumno debe redactar y elaborar la respuesta por escrito o en forma de respuesta oral. Frente a los exámenes multirrespuesta, permite un mayor ejercicio de razonamiento por parte del alumno. Sin embargo, dado la alta susceptibilidad de introducción de valoraciones subjetivas en la corrección que este tipo de preguntas presenta, suelen ser bastante rechazados por parte de los alumnos.
La realización de exámenes orales está cada vez más en desuso, dado que su única diferencia con las preguntas de desarrollo escritas es la del empleo de las habilidades comunicativas del estudiante, que pueden ser evaluadas por otro tipo de actividades más allá de la evaluación de la materia, como la presentación oral de trabajos y, por otro lado, requiere mucho más esfuerzo que el examen escrito.

En este punto es importante plantearse el porqué de la importante proliferación de los exámenes de tipo multirrespuesta, a lo que podemos dar varias contestaciones: en primer lugar, son exámenes relativamente objetivos, como se señalaba antes, ya que las respuestas correctas son fácilmente contrastables y comparables en distintos ejercicios, aunque más adelante discutiré hasta qué punto esto se debe considerar objetivo. También se trata de exámenes de corrección relativamente fácil cuando el docente se enfrenta a cientos de ejercicios. Por último, cabría preguntarse si este aumento se puede deber en parte a una posible adaptación del método docente al examen MIR (ésta es una de las creencias generalizadas entre los alumnos).

Con respecto a esto, convendría hacer una aclaración al respecto de si una evaluación a base de preguntas multirrespuesta puede considerarse objetiva. Efectivamente, las respuestas planteadas suelen ser objetivamente correctas, pero no hay que confundir esto con la esencia de la evaluación objetiva como método para estimar los conocimientos, aptitudes y rendimiento de los alumnos, dado que una evaluación sobre, por ejemplo, la realización de un determinado proceso quirúrgico, no puede ser objetiva si se evalúa únicamente con un examen tipo test, que se ve limitado a la evaluación de conocimientos y requerirá de otros métodos para valorar las aptitudes del alumno en ese determinado proceso. Por ello, el hecho de que una respuesta sea objetivamente correcta no implica una evaluación objetiva.

Resulta especialmente llamativa la escasa atención que se presta a la evaluación de competencias prácticas en nuestro país. Tal como señala la Conferencia Nacional de Decanos de Facultades de Medicina, 'lo que no se evalúa, se devalúa', y por ello, quizá éste haya sido uno de los condicionantes de la devaluación del contenido práctico de la formación de pregrado.

Otro de los rasgos característicos de los procesos evaluativos en nuestro país es que tienen lu- 
gar en base a periodos finales de exámenes en los cuatrimestres, más que en base a una evaluación continua integrada en el programa formativo de manera mayoritaria. Sin dejar de lado que ambos procesos no son excluyentes y que pueden beneficiarse mutuamente, la falta de la evaluación continua nos debe hacer reflexionar sobre si la forma adecuada de fomentar el estudio a lo largo de la vida (life-long learning), uno de los objetivos fundamentales del proceso a Bolonia, consiste en evaluar al alumno una sola vez al año. También debemos preguntarnos si se consigue una evaluación más objetiva con un único examen, por muy extenso que pueda ser, o con un proceso de evaluación constante, o si no estamos desaprovechando la oportunidad de aprendizaje intrínseca a la evaluación.

En resumen, actualmente, la evaluación de los estudiantes de medicina de nuestro país se hace predominantemente en torno a dos elementos comunes: predominio de la evaluación teórica frente a la evaluación práctica, tanto para competencias teóricas como prácticas, y evaluación basada de forma mayoritaria en exámenes finales en detrimento de la evaluación continua.

\section{Perspectivas de futuro sobre la evaluación del estudiante de medicina en nuestro país}

La adaptación al EEES debería implicar un cambio radical en la metodología docente y, como tal, no se puede dejar de lado la evaluación. La revalorización de las competencias prácticas y del médico, que pasa de 'saber' a 'saber hacer', sólo podrá alcanzarse plenamente cuando existan mecanismos que certifiquen de la manera más objetiva posible que el estudiante ha alcanzado los objetivos planteados. Es evidente que con los métodos que actualmente predominan en nuestras facultades esto no se puede conseguir a todos los niveles.

Sin embargo, son varias las facultades que ya andan en esa dirección. Como muestran los resultados de una encuesta pasada por la Comisión InfoMIR del CEEM -comisión que estudia las propuestas y novedades sobre el sistema de formación MIR, de cara a la mesa redonda del III Congreso de Educación Médica del CEEM (Albacete, 22-23 de abril de 2010), titulada 'Las facultades de medicina en el marco de la nueva prueba de acceso al sistema de formación especializada'-, a pesar de la escasa presencia de la evaluación práctica en nuestras facultades, los estudiantes en general consideran que ésta se hace de una manera objetiva (un $83 \%$ en las facultades de creación posterior al 2008 y un $76 \%$ en las de creación anterior).

Es más, según esta misma encuesta el $43 \%$ de las facultades ya contaban con pruebas de evaluación clínica objetiva y estructurada (ECOE) en los planes de estudios vigentes en el curso 2009-2010. A pesar de que la gran mayoría de nuestras facultades no tiene este tipo de pruebas implantadas, podemos considerarlo como un primer indicador de cambio.

\section{Evaluación del profesorado y de los planes de estudios por parte de los estudiantes}

El estudiante, como un miembro más de la universidad, no debe contentarse solamente con ser un agente pasivo en su paso por la facultad. Debe ser capaz también de intervenir en los procesos de mejora de la docencia y de construcción de auténtica universidad. La perspectiva global que adquiere el alumno debe complementar a la de profesores, personal de administración y servicios y al resto de la comunidad universitaria. Por ello, desde el CEEM y las delegaciones de alumnos siempre hemos intentado fomentar esta participación crítica del alumnado dentro de las facultades.

Actualmente, las herramientas de las que disponemos los estudiantes para valorar a los profesores son insuficientes. En la mayoría de los casos se basan únicamente en encuestas cerradas cumplimentadas puntualmente a lo largo del curso para valorar el trabajo de nuestros profesores. Rara vez los resultados de estas encuestas conllevan repercusión alguna y muchas veces sus resultados caen en el olvido. Estas encuestas suelen ser muy genéricas y raramente pueden ahondar en la diversidad de asignaturas que tiene nuestra carrera.

En cuanto a la evaluación de los planes de estudio, la participación de los estudiantes, a través de sus representantes, debe ser esencial, no sólo como usuarios, sino como los únicos capaces de aportar una visión global al proceso. Los estudiantes de medicina tenemos la suerte de contar 
con asociaciones de estudiantes y órganos representativos con una implantación sin precedentes en nuestro país y debemos ser capaces de formarnos y trabajar en educación médica para poder aportar el máximo posible en el momento actual, tal como las propias instituciones educativas han señalado [3].

\section{Examen MIR ¿evaluación final objetiva?}

Por último, no podemos olvidarnos de la prueba de acceso al sistema de formación especializada o examen MIR. El examen MIR es una de las pruebas determinantes para los estudiantes de medicina, sobre todo para los alumnos de los últimos cursos. Prueba de ello es el importante debate existente dentro de nuestro colectivo con respecto a las actuales propuestas de modificación tanto del sistema como de la prueba MIR.

El examen MIR es una prueba escrita de ámbito nacional que desde la convocatoria del año 2009 cuenta con 225 preguntas multirrespuesta, 10 de las cuales se apoyan en imágenes. Tradicionalmente, el puesto final del estudiante se obtenía al dar un $75 \%$ del peso al valor obtenido en la examen, y el $25 \%$ restante, al expediente académico. Sin embargo, recientemente, a través de la correspondiente Orden Ministerial [4], esto ha cambiado y el expediente académico ha pasado a valer tan sólo un $10 \%$, de acuerdo con el planteamiento que ha defendido, entre otras organizaciones, el CEEM [5].

Por lo explicado anteriormente, no podemos considerar un examen tipo test como una evaluación objetiva final del médico recién egresado, dado que en el momento actual este examen no es capaz de medir mucho más que los conocimientos del estudiante. ¿Qué sentido tiene entonces realizar un examen de ámbito nacional para entrar en el sistema de formación especializada? El de equiparar. Si bien no está demostrado, parece existir una importante desigualdad en los métodos evaluadores de nuestras facultades. Por ello, elegir plaza en base al expediente como criterio puede ser potencialmente injusto para los estudiantes formados en aquellas facultades más exigentes. Con el fin de clarificar este aspecto, la Comisión InfoMIR del CEEM lleva mucho tiempo trabajando en el 'Estudio InfoMIR', que pretende desvelar si finalmente existe alguna relación entre el puesto MIR final y el valor del expediente en función de la facultad de origen.

En conclusión, el examen MIR no puede considerarse un examen objetivo final para los estudiantes de medicina, sino como una prueba equitativa que permite comparar a los candidatos con el fin de ordenarlos. Si bien la incorporación de mayor número de casos clínicos y preguntas apoyadas en imágenes constituyen una importante ayuda para potenciar la dimensión clínica del examen, como el CEEM defiende, resulta improbable que podamos encontrar en un examen tipo test la respuesta a la evaluación objetiva final de un estudiante de medicina..

\section{Bibliografía}

1. Ley $44 / 2003$ de Ordenación de las Profesiones Sanitarias (LOPS). BOE n. ${ }^{\circ} 280$. p. 41442-58.

2. Universidad Autónoma de Madrid. Plan de estudios de la licenciatura de Medicina. 1999. URL: http://www. uam.es/centros/medicina/planes_de_estudio.html.

3. Prague Communique. Towards the European Higher Education Area. URL: http://www.bologna-berlin2003. de/pdf/Prague_communiquTheta.pdf.

4. Ministerio de Sanidad y Política Social. Orden SAS/2158/ 2010. BOE n. ${ }^{\circ} 191$. p. 69167-70.

5. Consejo Estatal de Estudiantes de Medicina. Actas de propuestas al Ministerio de Sanidad y Política Social de las LX Jornadas Estatales de Estudiantes de Medicina, 2010. URL: http://www.ceem.org. 